\title{
Mathematics Education Students' Understanding of Equal Sign and Equivalent Equation
}

\author{
Baiduri $^{1}$ \\ ${ }^{1}$ Mathematics Education Department of University of Muhammadiyah Malang, East Java, Indonesia \\ Correspondence: Baiduri, University of Muhammadiyah Malang, East Java, Indonesia. E-mail: \\ baiduriumm@gmail.com
}

Received: March 23, 2015 Accepted: October 22, 2015 Online Published: October 26, 2015

doi:10.5539/ass.v11n25p15 URL: http://dx.doi.org/10.5539/ass.v11n25p15

\begin{abstract}
The objective of this paper is to analyse matemathics education students' understanding of the equal sign, their strategies in solving the equivalent equations and the relationship between the two. Data were collected through responses from 167 first year students of mathematics education in University of Muhammadiyah Malang, East Java, Indonesia to the assigned tasks and the data were descriptively analysed using a Chi-square statistics. The results of the analysis showed that their operational understanding of the equal sign is more dominant than their relational conception. In solving equivalent equations, they tended to adopt operational procedures by making solutions, comparisons and substitutions, instead of paying attention to the existing relations in equivalence, called a strategy to recognize equivalence. No significant relations exist between students' understanding of the equal sign and their strategies in solving equivalent equations. Then gender and repondents` origin of areas are also discussed.
\end{abstract}

Keywords: equal sign, equivalence, equivalent equation

\section{Introduction}

Any algebra reasoning depends on the understanding of various main ideas. Equivalence can be said to one of the most basic ideas. And the understanding of equivalence is not separated from that of the concept of the equal sign, meaning that any understanding of the concept of the equal sign and of equivalence is inseparable. The understanding of the equal sign is an important matter in the mathematics language in general, especially in algebra and arithmetic. Researches showed that teachers really expected that there are many students who may understand the equal sign as relational, since it is a very basic problem for learning algebra (Asquith et al., 2007). But, students' difficulties in interpreting the equal sign are well documented (Knuth et al., 2006; Knuth et al., 2008).

The equal sign is usually introduced as an operational sign instead of relational sign of equivalence in the senior high school curriculum (McNeil \& Alibali, 2005b). A relational perspective of the equal sign is defined as "seeing expressions and equivalence as a whole, paying attention to the relation between and in the expression and equation" (Jacobs et al., 2007). Carpenter et al. (2005) showed that many students tended to count the both sides of $8+4=\ldots+5$ to find the true answer. On the contrary, students with relational thinking may see that 5 is one of the parts which is more than 4 and that the sum in the box should become one of the part that is less than 8. Students with relational thinking may help them use expressive characteristics of algebra and numeral operations by not merely doing arithmetic (Carpenter et al., 2003, 2005; Stephens, 2008). It means that one of the standards students should master in order to be able to think relationally is the right understanding of the meaning of the equal sign.

Students' misunderstanding of the equal sign that has been being studied for more than thirty years shows that students have long had difficulties in relational thinking (Bernstein, 1974; Ginsburg, 1989; Hiebert, 1984; Kieran, 1981; Li et al., 2008). Ability to define the meaning of the symbol of the equal sign is important, and it has been related to some success in algebra (Knuth et al., 2006) and further success in the courses of advanced mathematics (Usiskin, 1995). It suggests that the equal sign be carefully taught in order to avoid students' misunderstanding and to ascertain that the relational meaning is from the equal sign (Baroody \& Ginsburg, 1983). Knowledge of the equal sign as an indicator of equivalence is a very basic form as the development of students' mathematics and serves as the main connector between arithmetic and algebra (Matthews \& Taylor, 2012). Students' adequate 
understanding of the equal sign does not happen instantly because the equal sign has been introduced to the students since they were in elementary schools when they were studying mathematics at schools and they had little time to learn this symbol in the next classes (Knuth et al., 2006). McNeil (2007) found that students' conception of equivalence was developing in line with their previous understanding. This misunderstanding might still happen up to higher education (Carpenter et al., 2003; Knuth et al., 2006). Based on the fact, this paper will analyze about mathematic education students' understanding of the equal sign, solve problems of equivalent equation and their relationship. Furthermore, the nature of the equal sign and equivalent equation based on the review of some related literatures will also be presented.

\subsection{Students' Understanding of the Equal Sign}

Jones et al. (2011) see the equal sign as relational, operational and substitution in nature. It is relational if the equal sign means that both sides possess the same value or something that is equal with another, operational if the equal sign is meant to be total amount, the work results and answer to a problem, and substitution if the equal sign is meant that both sides are exchange one another, meaning that the right side may be substituted with the left side or a side may be replaced with another side.

Researchers in general explain that students' conception of the equal sign is as operational or relational conception (MacGregor \& Stacey, 1997; Carpenter et al., 2003; McNeil \& Alibali, 2005b; Knuth et al., 2006; Molina \& Amboroso, 2008; Molina, Castro, \& Castro, 2009). Students with operational conception see the equal sign as a sign to "do something" (for instance, stating that the solution for " $4+3=\ldots+2$ " is 9), meanwhile students with relational conception admit that the equal sign shows equivalence. A good conception to be developed of the equal sign for elementary and junior high school students is relational understanding. It is important because the equal sign symbolizes the similarity of expression or quantity expressed by each side of the equation. (Carpenter et al., 2003; McNeil \& Alibali, 2005a). Relational understanding of the equal sign will support better algebra competence, including skills in solving equation and algebra reasoning (Alibali et al., 2007; Jacobs et al., 2007, Kieran, 1992; Knuth et al., 2006). It means that building relational understanding of the equal sign is very important especially in algebra and mathematics in general.

\subsection{Students' Understanding Of Equivalence}

Researches in cognitive development and mathematics education have shown that students try to struggle to understand mathematical equality, especially in symbolic forms (Alibali, 1999; Baroody \& Ginsburg, 1983; Behr, Erlwanger, \& Nichols, 1980; McNeil, 2008). Mathematic equivalence is the relationship between two quantities that may be interchanged. This mathematic equivalence may be said as the most important concept to develop students' algebraic thinking (Falkner, Levi, \& Carpenter, 1999; Knuth et al., 2006).

When understanding the meaning of the equivalence of expression, Zwetzschler \& Prediger (2013) adopted an approach to meaning from the equal sign. If the equal sign is understood as operational, the equivalence is meant as transformational activities. If understood as relational, the equivalence is considered as comparing expressions (Kieran \& Sfard, 1999). It is then also stated that two expressions are said to be equivalent if: 1) description equivalence (if expressions depict the same phenomenon; the same geometric patterns, the same functions, the same situation), 2) embedded equivalence (if expressions posses the values for all substituted numbers; and 3) transformation equivalence (if an expression may change into another in line with transformation rules). The meaning of equivalence of expressions 1) and 3) is a relational perspective of an expression, while meaning equivalence of expression 2) is focus on an operational perspective.

A relational perspective is very important because it is needed by students in learning to solve algebraic equations using operation in both sides (for example, $5 x-5=2 x+1$ ). Moreover, it is also important to understand that transformation made in the process of solving equation should still maintain equivalence (namely, changing an equal equation). Student' difficulty in making mathematical equality proved to be long term and strong, and to be still existed among students in some secondary schools, colleges, and even in universities (Knuth et al., 2006; McNeil \& Alibali, 2005a). This condition is bad since an individual who does not develop a right understanding of mathematical equality will have difficulty in mathematics and science. Steinberg, Sleeman, dan Ktorza (1990) found that there were many eighth and ninth year students who knew how to use transformation to solve equation, but many who did not make use of knowledge of equivalence to determine whether the two equations given were equivalent. It means that there are many students who cannot posses some adequate conception of equivalence in mathematics.

\subsection{The Present Study}

The objective of this present paper is to analyze about mathematic education students' understanding of the equal 
sign, solve problems of equivalent equation and their relationship. Based on this objective, research problems are formulated as follows:

1) How is the mathematics education students' understanding of the equal sign?

2) How do the mathematics education students solve problems of equivalent equation?

3) Is there any relationship between the mathematics education students' understanding of the equal sign and the solution of the problems of equivalent equation?

\section{Method}

\subsection{Participants}

Participants are 167 the first semester mathematics education students of University of Muhammadiyah Malang, East Java, Indonesia, joining in the algebra course in the 2013-2014 academic year. They consist of 41 men and 126 women, where 123 students come from Java, and the rest 44 students from out of Java. Their average age is 18.48 year and deviation standard is 0.81 .

\subsection{Instrument}

The instrument of this present research referring to Knuth et al. (2008), Asquith et al. (2007), Alibali et al. (2007) and Knuth et al. (2005) was used to describe mathematics education students' understanding of the equal sign and strategies they adopted in solving the equivalent equation.

2.2.1 The Task of the Equal Sign (T1)

The following questions are the statement about $7+8=15$

(1) The arrow refers to a symbol. What is the name of the symbol?

(2) What is the meaning of the symbol?

(3) Can the symbol have different meanings? If yes, explain!

\subsubsection{The Task of the Equivalent Equation (T2)}

(P1)Does $m$ have equal values in the equation of $2 m+15=31$ and of $2 m+15-9=31-9$ ? Give your reason(s)!

(P2) In the equation of $a+18=35$, the value of $a$ is17. Can you use the data to determin the value of $a$ in the equation of $a+18+27=35+27$ ? Give your reason(s)!

\subsection{Data Collection}

The data collection was focused on the students' responses/written answers when they were given tasks of the equal and equivalent equation signs. The data were collected in two sessions before the first algebra course began. In Session I, students completed the task of the equal sign for 2 to 7 minutes. In Session II, they completed the task of the equivalent equation for 5 to 15 minutes.

\subsection{Data Analysis}

Analysis was made by coding each students' answer for each task like in Knuth et al. (2008), Asquith et al. (2007), Alibali et al. (2007) and Knuth et al. (2005). Then it is said that in order to have a validity in the coding procedures, the coding was made by two persons. The second coder recoded about $50 \%$ of the data. The agreement between the two coders was about $95 \%$ for each problem in the tasks of the equal and equivalent equation signs. Then the data were descriptively analyzed and using the chi-square statistics since the result variable is in the categorical form. All the statistical analyses used the software SPSS 17 with the significance level (alpha) of 0.05 .

\section{Results and Discussion}

On the basis of the students' written responses to the assigned tasks, the focused was given to their understanding of the equal signs in general, and especially their relational understanding, to the strategies and the relationship between the two.

\subsection{Understanding of the Equal Sign}

Students' responses to parts (2) and (3) in the task T1 are coded with relational (RE), operational $(O)$, operational-relational (O-RE), or others, where the majority of responses were under the first three categories. Responses were coded as relational if the equal sign means that the two sides possess the same value or something is the same or has similarity with others, as operational if the equal sign is meant to be the total (add) of work results or answers to problems, as O-RE if students respond operationally and relationally, and as other 
categories if the responses show "is", connectors or separators/dividers between the left and right sides of the equal. The description of the equal sign viewed from gender is shown in Table 1.

Table 1. Students' understanding of the gender-based equal sign

\begin{tabular}{llllll}
\hline GENDER & OPERATIONAL $(\mathrm{O})$ & RELATIONAL $(\mathrm{RE})$ & O-RE & OTHERS & TOTAL \\
\hline FEMALE & 47 & 46 & 29 & 4 & 126 \\
MALE & 15 & 13 & 11 & 2 & 41 \\
TOTAL & 62 & 59 & 40 & 6 & 167 \\
\hline
\end{tabular}

From Table 1, it is seen that female students with relational conception make up $36.52 \%$ of the total female students or $27.55 \%$ from the whole students. Meanwhile there are $31.71 \%$ of the male students with relational conception or $7.78 \%$ from the whole students. Female and male students with relational conception are $35.33 \%$ from the whole students. But, if they are combined (those with relational and operational-relational conceptions), there are $59.52 \%$ female students (from the whole female students) possessing relational conception, or $44.91 \%$ from the whole students. And there are $58.54 \%$ of male students with relational conception from the whole male students or $14.37 \%$ from the whole students. Meanwhile female students who have understanding of the equal sign as operational make up $60.32 \%$ from the whole male students, or $45.51 \%$ from the whole students and there are $63.42 \%$ of male students with operational conception from the whole male students, or $16.77 \%$ from the whole students. The proportion of understanding is presented in Figure 1.

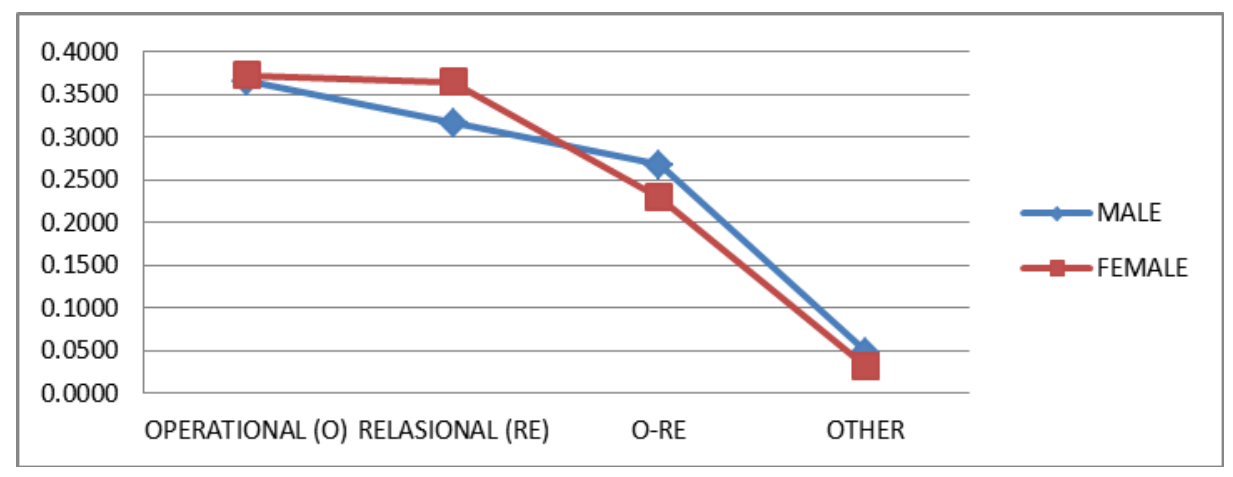

Figure 1. The proportion of female and male students in understanding the equal sign

Then, a description is also made about the equal sign viewed from the areas, Java, or out of Java because the facilities of education in Java tend to be better than those of out of Java. This understanding is presented in Table 2.

Table 2. Students' understanding on the equal sign based on origin of area

\begin{tabular}{llllll}
\hline ORIGIN & OPERATIONAL $(\mathrm{O})$ & RELATIONAL $(\mathrm{RE})$ & O-RE & OTHERS & TOTAL \\
\hline JAVA & 47 & 45 & 29 & 2 & 123 \\
NON JAVA & 15 & 14 & 11 & 4 & 44 \\
JLH & 62 & 59 & 40 & 6 & 167 \\
\hline
\end{tabular}

From Table 2, it is known that the percentage of students from Java, who have pure relational conception is $36.59 \%$ from the whole number of students in Java or $26.95 \%$ from the whole number of students. Meanwhile the students from non Java areas who have pure relational are $31.82 \%$ of the students in Java or $8.38 \%$ of the whole students. The percentage of students from Java and out of Java who possess relational conception is $31.82 \%$ of the students in Java or $8.38 \%$ of the whole students. Students from Java and non Java areas who have pure relational conception make up $35.33 \%$ of the whole students. However, if they are combined namely those with relational and operational-relational conceptions, there are $60.16 \%$ students with relational thinking from 
the whole students from Java or $44.31 \%$ of the whole students and there are $56.82 \%$ of students from Java areas who have relational conception from the whole students from Java areas or $14.19 \%$ of the whole students. Whereas, the percentage of students from Java understanding the equal sign as operational is $61.79 \%$ of students from Java or $45.51 \%$ of the whole students and there are $59.19 \%$ students from out of Java who have operational conception from the whole students from non Java areas, or $15.57 \%$ of the whole students. The proportion of understanding of the equal sign based on the origin of area is presented in Figure 2.

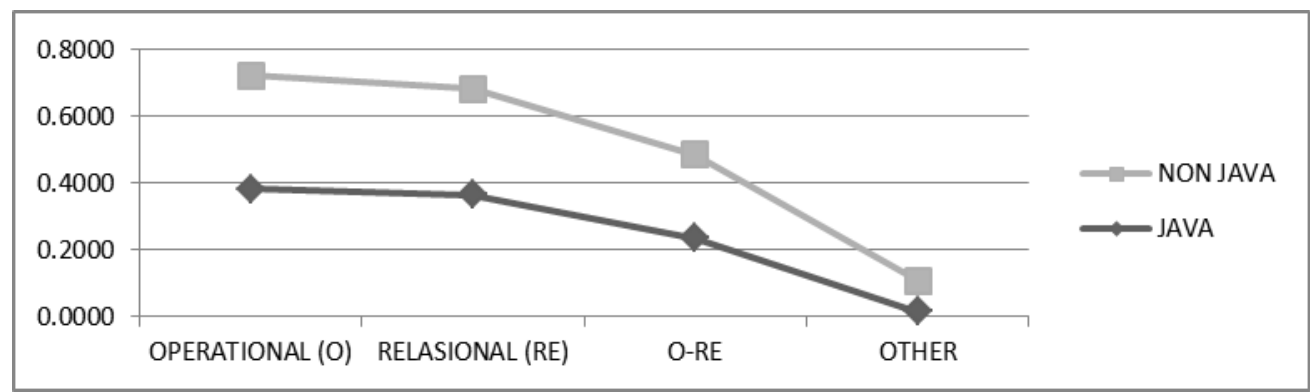

Figure 2. The proportion of understanding of the equal sign based on areas

Then, it is seen whether there is a relationship between the understanding of the equal sign from the sex and the origin of areas. Based on the chi-square test, $x^{2}(3, \mathrm{~N}=167)=0.644$ and $p$-value $=0.886>0.05$ are obtained, so that it can be stated there there is no significant relationship between gender and the understanding of the equal sign. It is also in line with the likelihood ratio test of which the value is 0.627 with the $p$-value $=0.89>0.05$. it is also the case if viewed from the origin of areas with the understanding of the equal sign. Although whether the understanding of the equal sign is grouped into relational or not, there is no significant relationship between gender and the origin of area and the understanding of the equal sign. It means that the understanding of the equal sign is not influenced by gender and the origin of area. Though there is not significant influence, it is known that the number of students with operational conception is higher than that of those with relational conception. It is not surprising results, because the same results are also obtained by previous researchers (Knuth et al., 2008; Asquith et al., 2007; Alibali et al., 2007; McNeil et al., 2006; Knuth et al., 2005; Falkner et al., 1999) for students of elementary and secondary schools. Since relational conception plays important roles in the success in completing equation and reasoning in algebra, it is really necessary to provide students with this conception as soon as possible.

\subsection{Strategies in Solving Problems of Equivalent Equation}

Responses to this case are coded on the basis of strategies adopted in the solutions. Students' strategies in solving problems are classified into one of the five categories: solve and compare (SC), recognize equivalence (RE), substitution (SU), answer only $(A O)$ or others. Responses are categorized into solve and compare, if students determine the solutions of the two equations and compare the end results. Responses are categorized into recognize equivalence, if (1) the response is based on the recognition that the transformation made in the two equation maintains an equivalent relationship or (2) the equivalence of the two equations is known without solving the equation or (3) the students make a transformation to one of the equations so that other equations are obtained or (4) the students make transformation in the two equations so that a new and identical equation is obtained.

Responses are categorized into substitution if (1) determining a solution for one of equations, then substituting the obtained solution with another or (2) substituting a solution for an equation with another equation to know whether the two equations have the same solution or (3) substituting a number in the two equations to know the two same equations. The strategy answer only is adopted if the student's response is merely to answer a number, without any comment, while the strategy others used if the students, besides what is mentioned before, also say: "no, because the equation does not contain variable" or "yes".

Based on the coding of the students' responses, the mostly-used strategy for problems (P1) and (P2) is solve and compare or substitution for problem (P2), while the least-used strategy is others. The distribution of students' strategies in solving problems of equivalent equation based on gender is shown in Table 3 . 
Table 3. Students' strategies in solving equivalent equation based on gender

\begin{tabular}{llllllllllll}
\hline \multirow{2}{*}{ GENDER } & SC & & RE & \multicolumn{3}{c}{ SU } & \multicolumn{3}{c}{ OTHER } & AO & \multirow{2}{*}{ TOTAL } \\
& P1 & P2 & P1 & P2 & P1 & P2 & P1 & P2 & P1 & P2 & \\
\hline FEMALE & 89 & 49 & 19 & 17 & 6 & 50 & 7 & 6 & 5 & 4 & 126 \\
MALE & 23 & 13 & 16 & 8 & 0 & 14 & 2 & 5 & 0 & 1 & 41 \\
TOTAL & 112 & 62 & 35 & 25 & 6 & 64 & 9 & 11 & 5 & 5 & 167 \\
\hline
\end{tabular}

From Table 3, it is known that the percentage of students using the solve and compare strategy in solving the problem $(\mathrm{P} 1)$ is $67.07 \%$ consisting of $53.29 \%$ female students and $13.77 \%$ male students, the problem (P2), $37.13 \%$ consisting of $29.34 \%$ and $7.79 \%$, female and male students, respectively. For the substitution strategy, it is adopted by $38.32 \%$ students, consisting of $39.94 \%$ female and $8.38 \%$, male students. There are $20,96 \%$ students, $11.38 \%$ female and $9,58 \%$ male students who adopt the recognize equivalence strategy for problem (P1), and for problem (P2), 14,97\% students, consisting of $10.8 \%$ female students and $4.79 \%$ male students. From the gender point of view, concerning with the solve and compare strategy, for the problem (P1), there are $70.63 \%$ female students from all female students, and $56.10 \%$ male students from all male students, while for the problem (P2), respectively $38.89 \%$, and $31.71 \%$. The recognize equivalence strategy is used by $15.08 \%$ female students for the problem (P1) and $13.49 \%$ for problem (P2) from all female students, by $31.71 \%$ male students for the problem (P1) and $39.02 \%$ for the problem (P2) from all male students. The substitution strategy is used by $4.76 \%$ female students for the problem ( $\mathrm{P} 1$ and $36.68 \%$ for the problem (P2) from all female students, and not used by male students for the problem (P1) and is used by $34.15 \%$ male students for the problem (P2) from all male students). Moreover, this strategy is almost not adopted by students for the problem (P1), because the solution for the two equations has not been given or known. It is different from the problem (P2), where the solution for the first equation has been given, so it is possible to substitute the solution into the second equation. The mostly used-strategies by female and male students in solving the equivalent equation are solve and compare and substitution strategies, instead of recognize equivalence strategy. These strategies are stable enough for each problem (P1 and P2). Compared with the strategies adopted by female and male students, female students used the solve and compare and substitution strategies more often, while male students tended to use the substitution strategy.

Then the relationship between gender and the strategies in problem solving is also explained. Based on the chi-square test for gender and problem solving strategies (P1), it is obtained the value of $\chi^{2}(4, \mathrm{~N}=167)=10.354$ and $p$-value $=0.035<0.05$ and $x^{2}(4, \mathrm{~N}=167)=4.077$ and $p$-value $=0.396>0.05$ for problem (P2). It means that there is a significant relationship between gender and problem solving strategies (P1), but no significant relationship exists between gender and problem solving strategies (P2). It is also known from the higher percentage of the difference between female and male students for the problem (P1) in each strategy than for the problem (P2). It means that gender has a significant relationship with the equivalent problem solving strategy if the two equivalences have not been given solutions, and the relationship is insignificant if one of the equations has been given a solution.

Then students' strategies based on the origin of areas will also be presented. The proportion of students' strategies in solving the equivalent equation based on the origin of areas is shown in Figure 3.

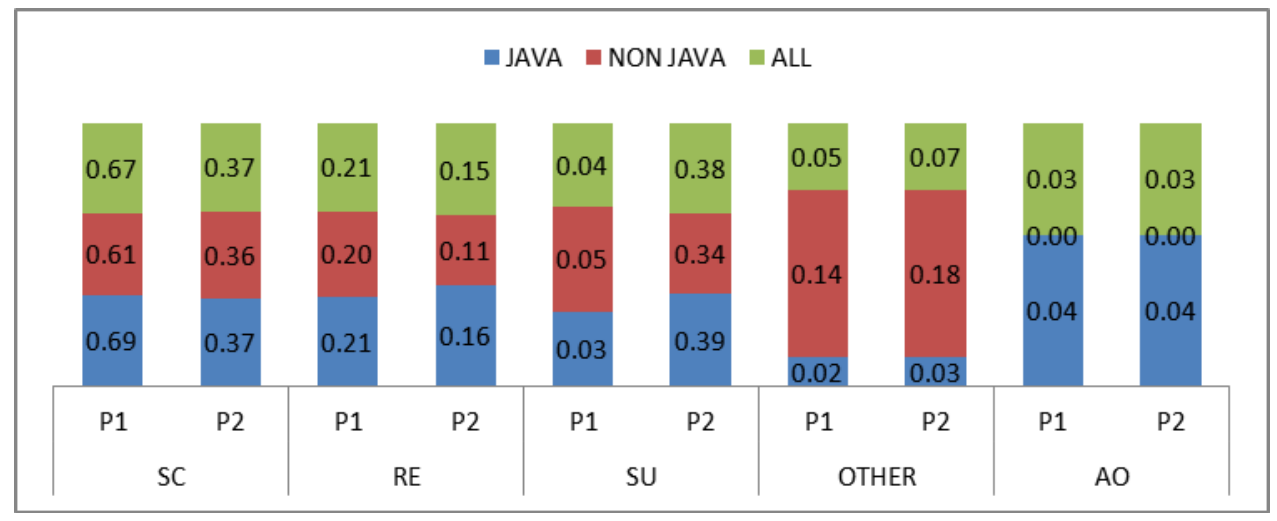

Figure 3. The proportion of the solution of equivalent equation based on area 
In Figure 3, it is shown that in each problem (P1 and P2), the proportion between students from Java and non Java for each each strategy is relatively the same. The highest proportion is on the solve and compare strategy for the problems ( $\mathrm{P} 1$ and $\mathrm{P} 2)$, followed by substitution strategy for the problem (P2) and recognize equivalence strategy for the problems (P1 and P2). In the three strategies, the proportion of students from Java is higher than that of non Java. It is surprising, remembering that in general facilities and infrastructure of education in Java are better than in non Java areas. As in the case of gender, in the problem (P2), the substitution strategy is adopted by more students either from Java or non Java. It is very different from the problem (P1), where almost no students adopt the strategy. In the problem (P2), the solution for the first equation has been given, so that this enables students to substitute the solution into the second equation while in the problem (P1), no solution for the second equation has not been provided or known.

Based on the chi-square test for the origin of areas and problem solving strategy (P1), it is obtained that $x^{2}(4, \mathrm{~N}$ $=167)=5.986$ and $p$-value $=0.200>0.05$ and for the problem $(\mathrm{P} 2), x^{2}(4, \mathrm{~N}=167)=11.559$ and $p$-value $=0.021$ $<0.05$. Therefore, it can be stated that there is no significant relationship between the origin of areas and the strategies of problem solving (P1), but, there is a significant relationship with the problem solving strategy (P2). It is contrary to the relationship between gender and problem solving strategy for equivalent equation. It means that the origin of area shows a significant relationship with strategies for solving equivalent problems if one of its equations is givens its solution and no significant relationship exists with strategies for solving equivalent problems if the two equations are not given their solutions yet. Moreover, it can be stated that the students' origin of area has not fully influenced their understanding of two equivalent equations. It is in line with Steinberg, Sleeman, and Ktorza's research (1990) stating that there are many students who did not make use of their knowledge of equivalence to determine whether two equations assigned are equivalent or not, although they were able to solve the equations. Therefore, an operational perspective in solving equations, commonly happen among students in elementary and secondary schools, seems not to be revised or left, even after years of experiences working with algebra (McNeil et al., 2010).

Then, it is explained whether there is a relationship between understanding of the equal sign and the strategies in solving problems of equivalent equations. The description of the two is shown in Table 4.

Table 4. Understanding of the equal sign and strategies in solving equivalent equations

\begin{tabular}{llllllllllll}
\hline \multirow{2}{*}{ Strategies/ Understanding } & SC & & RE & \multicolumn{1}{c}{ SU } & \multicolumn{3}{c}{ OTHER } & AO & \multirow{2}{*}{ Total } \\
& P1 & P2 & P1 & P2 & P1 & P2 & P1 & P2 & P1 & P2 & \\
\hline Operational (O) & 38 & 24 & 13 & 5 & 3 & 24 & 3 & 4 & 5 & 5 & 62 \\
Relational (RE) & 42 & 19 & 11 & 13 & 2 & 23 & 4 & 4 & 0 & 0 & 59 \\
O-RE & 27 & 17 & 9 & 6 & 2 & 14 & 1 & 3 & 1 & 0 & 40 \\
Other & 5 & 2 & 1 & 1 & 0 & 3 & 0 & 0 & 0 & 0 & 6 \\
Total & 112 & 62 & 34 & 25 & 7 & 64 & 8 & 11 & 6 & 5 & 167 \\
\hline
\end{tabular}

From Table 4, it is seen that the percentage of students who use the recognize equivalence strategy for the problem (P1) amount to $32.35 \%$ of students adopting the strategy or $18.64 \%$ students who understand the sign as a relational concept. Meanwhile, for the problem (P2), there are $52.00 \%$ students who use the strategy or $22.03 \%$ students who understand the sign as a relational concept. If the relational and the operational-relational understandings are combined, the percentage of students who use the recognize equivalence strategy is $58.82 \%$, or $20.20 \%$ students who understand the sign as a relational concept. Meanwhile for the problem (P2), there are $76.00 \%$ students who use the strategy or $19.19 \%$ students who understand the sign as a relational concept. Many students posses a relational conception of the equal sign, but in their problem solving strategy, they have not recognize equivalence. For the problem (P1), there are $71.19 \%$ and for the problem (P2) there are $32.20 \%$ students who make use of solve and compare strategy, and for the problem (P2), there are $39.98 \%$ students who adopt the substitution strategy. It means that there are few students who make use of their relational understanding of the equal sign in solving equivalent equations. This result is in line with McNeil et al. (2006) that there are many high secondary high school students who understand the equal sign with a relational conception, but they cannot use them in solving equation problems. What is more interesting is that students who dominantly solve problems using the recognize equivalence are those with an operational conception of the equal sign, making up $38.24 \%$ students for the problem (P1), but the percentage is lower $(20.00 \%)$ for the Problem (P2). This shows that students are still inconsistent in making use of their understanding of the equal sign to 
solve equivalent equation problems.

Based on the chi-square test of the understanding the equal sign and strategies of solving problem (P1), it is obtained that $x^{2}(12, \mathrm{~N}=167)=8.521$ and $\mathrm{p}$-value $=0.743>0.05$ and for the problems $(\mathrm{P} 2)$ it is $x^{2}(12, \mathrm{~N}=167)$ $=13.971$ and $\mathrm{p}$-value $=0.303>0.05$. So it can be stated that there is not significant relationship between students' understanding of the equal sign and strategies the used in solving equivalence problems (P1) and (P2). It means that although the problem is on the equivalent equations, but if the problems are presented a little different from usual students will respond them differently in accordance with their background. Moreover, it can be stated that they still have not understood when two equations are said to be equivalent. It is different from Knuth et al. (2006) stating students possessing a relational understanding of the equal sign perform better when they solve linear equations than those without such a relational understanding. This phenomenon is in line with what is stated by LeFevre, Sadesky, \& Bisanz (1996) that in mathematics, educated persons often make use of less sophisticated strategies to solve problems as expected. This condition in cognition is necessary to understand because it may give clues on learning characteristics and cognitive development (McNeil et al., 2010).

\section{Conclusion and Remark}

The concept of the equal sign and equivalence is two important elements in algebra. Successes in algebra will open any chances to reach success in either advanced mathematics or future career. Therefore, the understanding of the equal sign concept an the equivalent equation is always given much attention at all levels of education. The understanding of a concept a student gains is heavily influenced by or is in line with previous understanding (McNeil, 2007). Most students still have an operational conception instead of a relational conception in understanding the equal sign. There are many students who still have a relational understanding of the equal sign, but they still cannot use it in solving equivalent equations.

The study is limited to the first semester of mathematics education students University of Muhammadiyah Malang, Indonesia. Nonetheless participants of research are from various regions in Indonesia. So that the results can be used as an illustration of the high school students' understanding of the equal sign and the equivalent equation. It is expected that the results of this present research may give some information to the developers of mathematics curriculum, authors of mathematics books and of mathematics learning so that they may be able to give more opportunities for elementary, secondary/university students to develop the two concepts correctly.

\section{References}

Alibali, M. W. (1999). How children change their minds: Strategy change can be gradual or abrupt. Developmental Psychology, 35, 127-145. http://dx.doi.org/10.1037/0012-1649.35.1.127

Alibali, M. W., Knuth, E. J., Hattikudur, S., McNeil, N. M., \& Stephens, A. C. (2007). A longitudinal examination of middle school students' understanding of the equal sign and equivalent equations. Mathematical Thinking and Learning, 9(3), 221-247. http://dx.doi.org/10.1080/10986060701360902

Asquith, P., Stephens, A. C., Knuth, E. J., \& Alibali, M. W. (2007). Middle school mathematics teachers' knowledge of students' understanding of core algebraic concepts: Equal sign and variable. Mathematical Thinking and Learning 9, 249-272. http://dx.doi.org/10.1080/10986060701360910

Baroody, A. J., \& Ginsburg, H. P. (1983). The effects of instruction on children's understanding of the "equals" sign. The Elementary School Journal, 84, 198-212. http://dx.doi.org/10.1086/461356

Behr, M., Erlwanger, S., \& Nichols, E. (1980). How children view the equal sign. Mathematics Teaching, 92, 13-15.

Bernstein, B. E. (1974). “Equation” means “equal”. The Arithmetic Teacher, 21, 697-698.

Carpenter, T., Megan, F., \& Linda, L. (2003). Thinking mathematically: Integrating arithmetic and algebra in the elementary school. Portshouth, NH: Heinemann.

Carpenter, T., Megan, F., \& Linda, L. (2005). Algebra in the elementary school: Developing relational thinking. Zentralblatt für Didaktik der Mathematik, 37, 53-59. http://dx.doi.org/10.1007/BF02655897

Falkner, K., Levi, L., \& Carpenter, T. (1999). Children's understanding of equality: A foundation for algebra. Teaching Children Mathematics, 6, 56-60.

Ginsburg, H. (1989). Children's arithmetic: How they learn it and how you teach it. New York: Van Nostrand.

Hiebert, J. (1984). Children's mathematical learning: The struggle to link form and understanding. The Elementary School Journal, 84, 496-513. http://dx.doi.org/10.1086/461380 
Jacobs, V., Megan, F., Carpenter, T., Levi, L., \& Battey, D. (2007). Professional development focused on children's algebraic reasoning in elementary school. Journal for Research in Mathematics Education, 38, 258-288.

Jones,I., Inglis, M., \& Gilmore, C. (2011). Imperative- and punctuative-operational conceptions of the equals sign. In C. Smith (Ed.), Proceedings of the British Society for Research into Learning Mathematics, 31(1).

Kieran, C. (1981). Concepts associated with the equality symbol. Educational Studies in Mathematics, 12, 317-326. http://dx.doi.org/10.1007/BF00311062

Kieran, C. (1992). The learning and teaching of school algebra. In D. A. Grouws (Ed.), Handbook of research on mathematics teaching and learning (pp. 390-419). New York: Macmillan.

Kieran, C., \& Sfard, A. (1999). The case of equivalent expressions. Focus on Learning Problems in Mathematics, 21(1), 1-17.

Knuth, E. J., Alibali, M. W., Weinberg, A., McNeil, N. M., \& Stephens, A. C. (2005). Middle school students' understanding of core algebraic concepts: Equality and variable. Zentralblatt für Didaktik der Mathematik (International Reviews on Mathematical Education), 37, 68-76. http://dx.doi.org/10.1007/BF02655899

Knuth, E., Alibali, M., Hattikudur, S., McNeil, N., \& Stephens, A. (2008). The importance of equal sign understanding in the middle grades. Mathematics Teaching in the Middle School, 13, 514-519.

Knuth, E., Stephens, A., McNeil, N., \& Alibali, M. (2006). Does understanding the equal sign matter? Evidence from solving equations. Journal for Research in Mathematics Education, 36, 297-312.

LeFevre, J. A., Sadesky, G. S., \& Bisanz, J. (1996). Selection of procedures in mental addition: Reassessing the problem size effect in adults. Journal of Experimental Psychology: Learning, Memory, and Cognition, 22, 216-230. http://dx.doi.org/10.1037/0278-7393.22.1.216

Li, X., Ding M., Capraro, M. M., \& Capraro, R. M. (2008). Sources of differences in children's understandings of mathematical equality: Comparative analysis of teacher guides and student texts in China and in the United States. Cognition and Instruction, 26, 195-217. http://dx.doi.org/10.1080/07370000801980845

MacGregor, M., \& Stacey, K. (1997). Students' understanding of algebraic notation: 11-15. Educational Studies in Mathematics, 33, 1-19. http://dx.doi.org/10.1023/A:1002970913563

Matthews, P., \& Taylor, R. (2012). Measure for Measure: What Combining Diverse Measures Reveals About Children's Understanding of the Equal Sign as an Indicator of Mathematical Equality. Journal for Research in Mathematics Education, 43(3), 220 - 254.

McNeil, N. M. (2007). U-shaped development in math: 7-year-olds outperform 9-year-olds on equivalence problems. Developmental Psychology, 43(3), 687-695. http://dx.doi.org/10.1037/0012-1649.43.3.687

McNeil, N. M. (2008). Limitations to teaching children $2+2=4$ : Typical arithmetic problems can hinder learning of mathematical equivalence. Child Development, 79, 1524-1537. http://dx.doi.org/10.1111/j.14678624.2008.01203.x

McNeil, N. M., \& Alibali, M. (2005a). Knowledge change as a function of mathematics experience: All contexts are not created equal. Journal of Cognition and Development, 6(2), 285-306. http://dx.doi.org/10.1207/s1 5327647jcd0602_6

McNeil, N. M., \& Alibali, M. W. (2005b). Why won't you change your mind? Knowledge of operational patterns hinders learning and performance on equations. Child Development, 76, 883-899. http://dx.doi.org/10.1111/j. 1467-8624.2005.00884.x

McNeil, N. M., Grandau, L., Knuth, E. J., Alibali, M. W., Stephens, A. C., Hattikudur, S., \& Krill, D. E. (2006). Middle-school students' understanding of the equal sign: The books they read can't help. Cognition and Instruction, 24, 367-385. http://dx.doi.org/10.1207/s1532690xci2403_3

McNeil, N. M., Johnson, B. R., \& Hattikudur, S. (2010). Continuity in reprentation between children and adult: Arithmetic knowledge hinder undergraduates' algebraic problem solving. Journal of Cognition and Development, 11(4), 437-457. http://dx.doi.org/10.1080/15248372.2010.516421

Molina, M., \& Ambrose, R. (2008). From an operational to a relational conception of the equal sign. Thirds graders' developing algebraic thinking. Focus on Learning Problems in Mathematics, 30(1), 61-80.

Molina, M., \& Castro, E. (2009). Elementary Students' Understanding of the Equal Sign in Number Sentence. Electronic Journal of Research in Educational Phycology, 17(7), 341-368. 
Steinberg, R., Sleeman, D., \& Ktorza, D. (1990). Algebra students' knowledge of equivalence of equations. Journal for Research in Mathematics Education, 22(2), 112-121. http://dx.doi.org/10.2307/749588

Stephens, A. (2008). What "counts" as algebra in the eyes of preservice elementary teachers? Journal of Mathematical Behavior, 27, 33-47. http://dx.doi.org/10.1016/j.jmathb.2007.12.002

Usiskin, Z. (1995). Why is algebra important to learn? American Educator, 31-37.

Zwetzschler, L., \& Prediger, S. (2013). Conceptual Challenges for Understanding The Equivalence Of Expressions - A Case Study. Proceedings of the 8th Congress of the European Society for Research in Mathematics Education (pp. 558-567). (CERME 8), Antalya, METU University Ankara.

\section{Copyrights}

Copyright for this article is retained by the author(s), with first publication rights granted to the journal.

This is an open-access article distributed under the terms and conditions of the Creative Commons Attribution license (http://creativecommons.org/licenses/by/3.0/). 